\title{
New approach using redox potential for freshness determination of fish and shellfish
}

\author{
Tri winarni AGUSTINI, ${ }^{*}$ Mongkol CHEEVAPORANAPIVAT, ${ }^{2}$ ChIDzuru UCHIDA, $^{2}$ \\ SHOICHI OKOUCHI, ${ }^{3}$ TORU SUZUKI, ${ }^{2}$ AND RIKUO TAKAI ${ }^{2}$ \\ ${ }^{*}$ Dept.of Fisheries, Faculty of Fisheries and Marine Science, Diponegoro University, Indonesia. e-mail: \\ tagustini@yahoo.com. \\ ${ }^{2}$ Food Engineering Laboratory, Dept. of Food Science and Technology, Tokyo University of Fisheries, 4-5-7, \\ Konan, Minato-ku, Tokyo 108-8477, Japan e-mail: see_mongkol@yahoo.com \\ ${ }^{3}$ Faculty of Engineering, Hosei University, Tokyo 184-8584, Japan
}

KEY WORDS:redox potential, freshness, fish, shellfish, $K$ value

\section{INTRODUCTION}

Freshness of fish is one of the most important aspects of quality and its assessment being of concern for many researchers. Study on evaluation of fish freshness had been conducted for a long time using several parameters such as biochemical, sensory and physical parameters. Many methods had been introduced to evaluate fish freshness, which were based on those parameters. For its application, however, simple, rapid, accurate and not expensive method will be concern by people who deal with fisheries product quality. Recently, study using redox potential (ORP) to evaluate fish freshness had been conducted using commercial fish of yellowfin tuna. The results showed that there was a correlation between ORP and fish freshness deterioration both at initial and later state of deterioration. (see Fig.1). It was found that the ORP value of yellowfin tuna after death gradually increased and reached the maximum value then decreased towards the later stage of deterioration. In order to understand this phenomenon, further study regarding the effect of antimicrobial agent on ORP change was carried out.

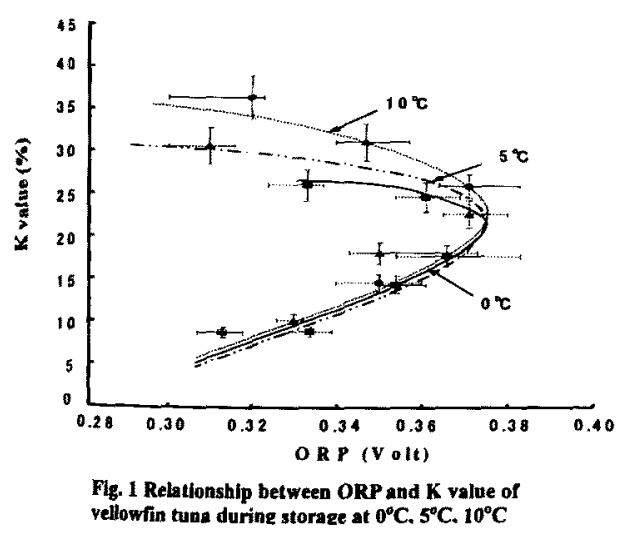

Moreover, further information between freshness and the ORP changes in various kinds of fish and shellfish are essential for actual utilization of this method. Therefore, the patterns of ORP change in fish and shellfish during chilled storage were investigated.

\section{MATERIALS AND METHODS}

Fish samples used in this study are jack mackerel (Trachurus japonicus) as dark-fleshed fish and red sea bream (Pagrus major), lizard fish (Saurida sp.), Japanese flounder (Paralichthys olevaceus) as white-fleshed fish. Kuruma prawn (Penaeus japonicus) and scallop (Patinopecten yessoensis) were selected as representatives of shellfish. All live fish samples were killed immediately by decapitation then filleted and wrapped with polyethylene bag prior to storage at $5^{\circ} \mathrm{C}$ for 7 days. Live kuruma prawns were stored as whole and then decapitated and removed the tails prior to measurement. Live scallops were killed by knife and removed from shells. Both shellfish were stored at $5^{\circ} \mathrm{C}$. The samples were taken and analyzed for ORP, $\mathrm{pH}$ by electrometer (Toko Chemical Co, Ltd. TPX-90i) ${ }^{2}$ and $\mathrm{K}$ value by modified HPLC method of Ryder $(1985)^{3)}$ respectively. The ORP and $\mathrm{pH}$ were measured at about $0.5-\mathrm{cm}$. depths inside each fish block and calculated in average. The yellowfin tuna was cut into block $\left(4 \times 4 \times 4 \mathrm{~cm}^{3}\right)$ and soaked in 500 ppm chlortetracycline solution at $10^{\circ} \mathrm{C}$ for 2 hours. After discharge the solution, the fish block was wrapped and stored at $10^{\circ} \mathrm{C}$ for 7 days. Change in ORP of antimicrobial treated sample was compared to the control (untreated). 


\section{RESULTS}

The relationship between ORP and $K$ value of various fish species is illustrated in Fig.2. Similar trend to that of yellowfin tuna was also found as the ORP increased along with $\mathrm{K}$ value. Thus ORP attained maximum value around 0.35 Volt and then decreased at a certain $\mathrm{K}$ value, depending on species. However, lizardfish showed slightly different where maximum ORP was relatively low (0.31 Volt) tendency while $\mathrm{K}$ value increased rapidly. Fig.3 depicts the effect of using antimicrobial agent on ORP change. The ORP value of antimicrobial treated sample was constant around 0.32 Volt, whereas that of control decreased sharply after 4 days. The ORP change of shellfish during storage is shown in Fig.4. Unlike scallop, kuruma prawn did not show sensitive response in ORP change during deterioration. Moreover, both shellfish have comparatively low maximum ORP values (0.175-0.275 Volt).

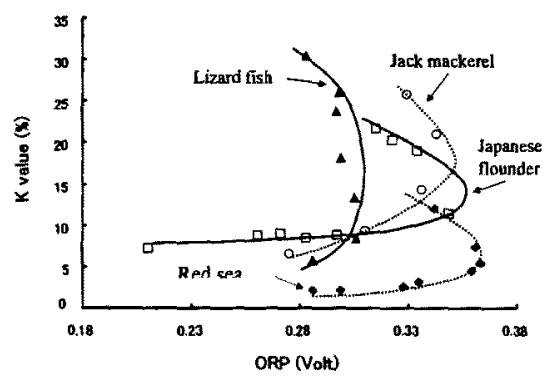

Fig. 2 Relationship between ORP and $K$ value of some marine fish

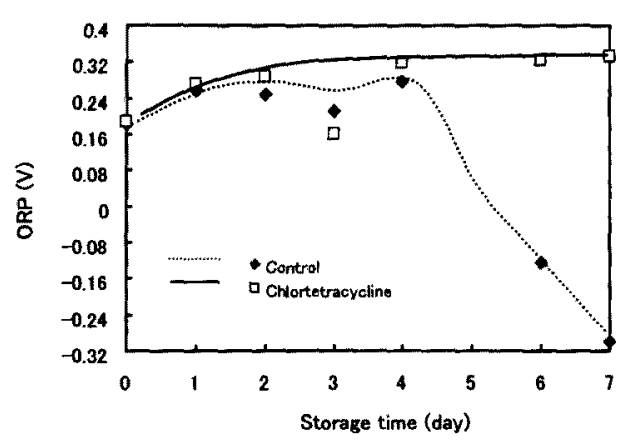

Fig. 3 Efrect of antínmicrobial agent on ORP change of yellownin tuns

\section{DISCUSSION}

In the previous study using yellowfin tuna, we found that changing in ORP up to its maximum value is considered as the state where fish can be eaten raw. This judgment was correlated well with $K$ value. ${ }^{4}$ Japanese flounder and red sea bream showed similar pattern to yellowfin tuna. The ORP reached a maximum value when $K$ value attained to comparatively low value of $6-7 \%$ for red sea bream and $15 \%$ for Japanese flounder. Sakaguchi and Koize $^{5)}$ reported a slow increase in $\mathrm{K}$ value in both fish species, even if the deterioration progresses.

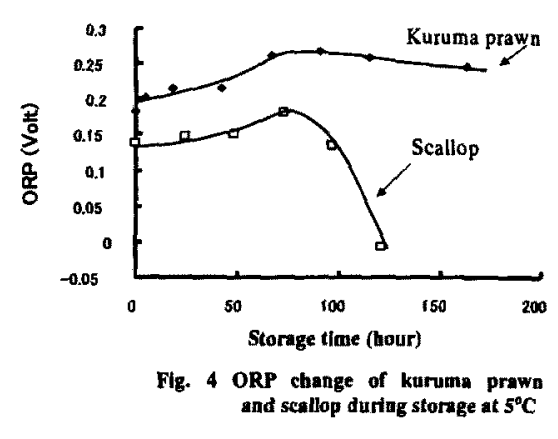

Therefore $K$ value is not considered as a suitable freshness indicator. On the other hand, the ORP is more sensitive for being used as a freshness index. Lizardfish is regarded as a rapid deteriorated fish, which is shown by more rapid changing in $\mathrm{K}$ value than ORP. This pattern was obviously different from the other fish. Depending on fish species, this maximum ORP will be different and attained at different $\mathrm{K}$ value. Increase in ORP initially during fish deterioration is due to the presence of redox couple such as $\mathrm{NAD}^{+}(\mathrm{H})$ and $\operatorname{NADP}^{+}(\mathrm{H})$. The later state of deterioration, which is characterized by decreased ORP, maybe due to the presence of microorganisms. It has been reported that initial bacterial contamination greatly influences the ORP change. ${ }^{6)}$ From our result, it was confirmed that the reduction of ORP value at later state of deterioration was mainly due to the presence of microorganisms since the microbial growth can be retarded by chlortetracycline. Shellfish showed different pattern of ORP change with a lower maximum value compared to fish. Difference in the chemical composition between fish and shellfish could probably cause this phenomenon. From our study, we consider that ORP can be possibly applied for determining freshness of both fish and shellfish.

\section{REFERENCES}

1. Agustini TW, Suzuki M, Suzuki T, Okouchi S, Takai R. The possibility of using oxidation-reduction potential to evaluate fish freshness. Fisheries Sci. 2001;67:547-549.

2. Okouchi S, Mizuno H, Kusatsuka K, Ishihara Y, Awaroji $Y$. Evaluation of aging index of hot and cold spring water by ORP. Onsen Kagaku (in Japanese). 1998;48:29-35

3. Ryder JM. Determination of adenosine triphosphate and its breakdown products in fish muscle by high performance liquid chromatography. J.Agric.Food Chem. 1985;33:678-680

4. Watanabe E. Measuring and controlling seafood quality in Japan. In: Sylvia G, Shriver Al., Morrissey MT (eds). Quality Control and Quality Assurance for Seafoods. USA. 1993;125-132

5. Sakaguchi M, Koize A. Freshness assessment of fish fillets using the Torrymeter and $\mathrm{K}$ value. In: Huss $\mathrm{HH}$ (eds). Quality Assurance in the Fish Industry. Elsevier. 1992; 333-338

6. Huss HH, Larsen A. The post mortem changes in the oxidation-reduction potential of fish muscle and internal organs. Proceed. X Int.Symp.LAMS., Polland. 1977; 265-279. 